\title{
Rational protein design of Bacillus sp. MN chitosanase for altered substrate binding and production of specific chitosan oligomers
}

\author{
David Gercke, Eva K. Regel, Ratna Singh and Bruno M. Moerschbacher * (D)
}

\begin{abstract}
Background: Partially acetylated chito-oligosaccharides (paCOS) have a variety of potential applications in different fields, but to harness their benefits, pure paCOS or well-defined paCOS mixtures are essential. For example, if one could produce fully acetylated $\left(A_{4}\right)$ and fully deacetylated $\left(D_{4}\right)$ tetramers in abundance, all possible variants of tetrameric paCOS could be generated reliably from them. A promising approach for generating defined paCOS is by enzymatic depolymerization of chitosan polymers using chitosanases, since these enzymes' subsite specificities directly influence the composition of the paCOS produced; however, enzymatic production of e.g. $D_{4}$ is challenging because the substrate is generally hydrolyzed further by most chitosanases. To overcome this, chitosanases could potentially be engineered so that upon hydrolyzing chitosan, they are unable to hydrolyze certain substrates, leaving well-defined oligomers intact in the hydrolysate.

Results: For this purpose, we performed rational protein engineering on the extensively studied GH 8 chitosanase CSN from Bacillus sp. MN. By specifically targeting residues with a predicted function in substrate binding, we created new muteins incapable of efficiently hydrolyzing the fully deacetylated tetramer $D_{4}$, and we were able to demonstrate efficient large-scale production of $\mathrm{D}_{4}$ with an altered version of CSN. Furthermore, we were able to uncover differences in the substrate positioning and subsite specificities of the muteins, which result in altered paCOS mixtures produced from partially acetylated chitosan polymers, with possibly altered bioactivities.

Conclusion: The value of protein engineering as a tool for the more efficient production of pure oligomers and potentially bioactive paCOS mixtures was demonstrated by the results and the suitability of specific muteins for the large-scale production of strictly defined, pure paCOS in a batch process was shown using the example of $\mathrm{D}_{4}$.
\end{abstract}

Keywords: Chitosan, Chito-oligosaccharides, Chitosanase, Glycoside hydrolase, Protein engineering

\section{Background}

Chitosan, a family of polymers consisting of $\beta$-1,4-linked $N$-acetyl-D-glucosamine (GlcNAc or A) and D-glucosamine (GlcN or D) units, is a group of commercially available molecules that are commonly generated by the partial chemical deacetylation of chitin. Producing chitosan is economically feasible since the required chitin is abundant; it is mostly derived from the crustacean shells discarded by the seafood industry [1]. Chitosans are

\footnotetext{
* Correspondence: moersch@uni-muenster.de

University of Muenster, Institute for Biology and Biotechnology of Plants, Schlossplatz 8, 48143 Münster, Germany
}

biocompatible, biodegradable, non-toxic, and show a variety of interesting bioactivities, but there is also a growing interest in producing partially acetylated chitooligosaccharides (paCOS) that can be derived from chitosans by partial depolymerization [1-4]. The oligomers share many of chitosans' positive properties, but they are additionally soluble at a neutral $\mathrm{pH}$ and have a lower viscosity, which is beneficial for their use in many areas, such as foliar application in agriculture [5]. In fact, paCOS produced by naturally occurring hydrolases might be responsible for some effects of chitosans in plant protection and wound healing $[2,6]$. Studies have

(c) The Author(s). 2019 Open Access This article is distributed under the terms of the Creative Commons Attribution 4.0 International License (http://creativecommons.org/licenses/by/4.0/), which permits unrestricted use, distribution, and 
found possible applications for paCOS in medicine, cosmetics, waste water treatment, and agriculture based on, e.g., their antimicrobial, antitumor, and immune-regulatory effects, but paCOS can also act as elicitors that induce various defense responses in plants or prime plants by inducing a state of enhanced defense in which they are more resistant to subsequent abiotic or biotic stresses [5, 7-10].

However, in some cases the reproducibility of paCOS bioactivities is problematic, as many studies have used poorly defined mixtures of paCOS varying in their degree of polymerization (DP), degree of acetylation (DA), and pattern of acetylation (PA) [2]. Just as it has been described for chitosan polymers, the DP and DA of paCOS are known to directly affect their bioactivities [11-14]; the PA's influence on paCOS bioactivities has been generally assumed, but only recently have studies started to decipher this $[9,15,16]$. Further, recent advances have now made it possible to fully characterize paCOS mixtures via quantitative mass spectrometric sequencing [17], but the major hurdle of reproducibly generating suitable paCOS mixtures or pure paCOS remains, rendering it difficult to determine how the PA specifically affects bioactivity. In this context, Hembach et al. recently achieved small-scale generation of all 14 possible tetrameric paCOS from the fully acetylated $\mathrm{A}_{4}$ and the fully deacetylated $\mathrm{D}_{4}$ [18]. While both substrates are already commercially available, they are extremely expensive and larger quantities would be required to allow bioactivity tests that could potentially give insights into the effect of the PA.

One promising approach to produce more defined paCOS involves using endo-acting chitosanases (E.C. 3.2.1.132) to depolymerize chitosans: As the process is enzymatic, it can be performed under mild conditions, is easy to control, and can potentially yield high amounts of oligomers with large DP. Chitosanases can be subdivided into families based on their amino acid sequences and into classes based on their subsite specificities [19, 20]. Four classes had previously been defined in this context. Class II enzymes are only able to cleave GlcN-GlcN linkages. Class I enzymes can additionally cleave GlcNAc-GlcN bonds and class III enzymes are capable of cleaving GlcN-GlcN and GlcN-GlcNAc linkages. The enzymes from class IV can cleave all bonds except the GlcNAc-GlcNAc bond that usually only chitinases can cleave [20,21]. More recently, a new classification system was proposed based not only on the specificities of the enzymes' subsites $(-1)$ and $(+1)$ directly adjacent to the hydrolyzed bond, but also on the subsites $(-2)$ and $(+2)$, taking into account not only absolute specificities but also relative preferences [22]. Subsite specificities and preferences of chitosanases for deacetylated or acetylated units are relevant for paCOS production because the composition of the generated oligomer mixtures is defined by them. Another important characteristic of chitosanases is the minimum DP of the end products they generate since oligomers with a higher DP often show stronger bioactivities [11, 12, 23, 24].

Chitosanases generally show lower hydrolytic efficiency on smaller substrates when not all subsites are occupied and accordingly, these oligomers accumulate during hydrolysis and can be purified. However, if the enzyme is capable of hydrolyzing the desired oligosaccharide product, the yield will be decreased as a result. Degradation of the product can be reduced by utilizing ultrafiltration (UF) membranes to separate enzyme and products. Experimental setups involving the use of UF membranes have been successfully applied to produce chitosan oligosaccharides in the past $[25,26]$. While effective, applying such setups involves higher initial investments and difficulties such as membrane fouling might occur [27]. Applying an enzyme incapable of hydrolyzing $\mathrm{D}_{4}$ would allow an effective and cheap production of the tetramer in a simple batch process. To find a suitable chitosanase for such an approach, one option is to identify and characterize naturally occurring enzymes for their ability to produce specific paCOS; alternatively, another option is to use rational protein design to alter already well-characterized enzymes.

The latter approach was chosen in this study because we wanted to obtain an enzyme unable to hydrolyze $\mathrm{D}_{4}$, a substrate that is normally readily hydrolysable by bacterial chitosanases [28-31]. Accordingly, the main products from low DA chitosan polymer are often $\mathrm{D}_{2}$ and $\mathrm{D}_{3}$ [32]. We performed engineering on a well-characterized, efficiently expressed enzyme with high activity: The chitosanase CSN from Bacillus sp. MN (BspCsnMN, GenBank accession no. JQ425408), subsequently referred to as CSN [33]. This enzyme can be classified as GH 8, former class III and current class A [22]. CSN contains seven subsites in its active center [34], and functional roles for a variety of residues have been identified [35]. Substrate binding first involves the substrate forming a "V-shape" conformation before hydrolysis, a process that is aided by the residues E59, W118, and Y270, among others $[34,36]$. Therefore, we attempted to abolish the activity of CSN on the fully deacetylated chitosan tetramer $\mathrm{D}_{4}$ by disrupting substrate binding at specific subsites. As $\mathrm{D}_{4}$ is readily accepted as a substrate and represents the smallest oligomer CSN can hydrolyze, any resulting muteins unable to cleave $\mathrm{D}_{4}$ could be used to produce high quantities of the oligomer which, together with fully acetylated $\mathrm{A}_{4}$, can serve as a starting material for the production of all partially acetylated chitosan tetramers at a larger scale [18]. Moreover, the hydrolysates produced with the muteins when acting on partially acetylated chitosan polymers are expected to differ from those produced with CSN wildtype, thus widening the 
spectrum of producible paCOS mixtures that could potentially also show altered bioactivities.

\section{Results}

To obtain muteins of CSN that display reduced activity on $\mathrm{D}_{4}$ but retain high activity on longer substrates, we generated CSN-E59A, CSN-W118A, and CSN-Y270A. In the active center of $\mathrm{CSN}, \mathrm{D}_{4}$ is forced into a "V-shape" conformation and is symmetrically positioned between the subsites $(-2)$ and $(+2)$ before hydrolysis $[35,36]$. By disrupting the substrate binding at either subsite $(-2)$ or subsite $(+2)$, the formation of the "V-shape" and a subsequent cleavage of the substrate should no longer be possible. Nonetheless, such mutations should not prevent activity on longer substrates with a DP of 5 and above, because these substrates can occupy additional subsites beyond $(-2)$ and $(+2)$ that could potentially stabilize their binding and enable formation of the correct substrate conformation and subsequent hydrolysis. For one mutein, since residue W118 forms stacking interactions with a sugar unit at subsite (-2) (Fig. 1) [34], we attempted to disrupt stable substrate binding from subsites $(-2)$ to $(+2)$ by changing the tryptophan at position 118 to alanine. For the resulting CSN-W118A, occupation of the subsite $(-3)$ could potentially stabilize binding of $\mathrm{D}_{5}$ or longer oligomers and allow efficient cleavage. Analogously, we created another two muteins by changing either Y270 at subsite $(+$ 2 ) or E59, positioned between subsites $(+1)$ and $(+2)$, to alanine. In these cases, $\mathrm{D}_{5}$ should still be able to occupy subsite $(+3)$ and achieve stabilized binding. CSN and the muteins were purified using Strep-tag II/Strep-Tactin affinity chromatography and analyzed via western immunoblotting (Additional file 1: Figure S1).

\section{Hydrolytic efficiency towards chitosan and $\cos$}

To check the muteins for a decreased activity on $\mathrm{D}_{4}$, we initially compared the product profiles from a low DA chitosan polymer (Fig. 2). As expected from previous studies, hydrolysates produced with CSN wildtype contained mainly $\mathrm{D}_{2}$ and $\mathrm{D}_{3}$ as end products. For both CSN-E59A and CSN-W118A, $\mathrm{D}_{4}$ was present in addition to $D_{2}$ and $D_{3}$, already indicating a reduced activity on the tetramer. For CSN-Y270A, the exchange of Y270 to alanine did not seem to disrupt the hydrolytic activity on $\mathrm{D}_{4}$, as this oligomer was not present in the hydrolysate; rather, increased amounts of $D_{1}$ and $D_{3}$ were detectable.

Kinetics on chitosan polymer DA $1.5 \%$ as well as on the oligomers $D_{4}$ and $D_{5}$ were recorded to verify these first findings (Fig. 3). CSN showed high activity on the polymer, and it was even slightly more active on $D_{5}$. By comparison, the tetramer $\mathrm{D}_{4}$ proved to be a poor substrate. The obtained value of $2.3 \mathrm{~s}^{-1}$ for the catalytic rate constant $\left(\mathrm{k}_{\mathrm{cat}}\right)$ on $\mathrm{D}_{4}$ was ca. tenfold lower than for the other two substrates, but efficient hydrolysis of $\mathrm{D}_{4}$ was still possible. Compared to CSN, the mutein CSN-Y270A showed a pronounced, consistently lower activity, where for all tested substrates, the $\mathrm{k}_{\mathrm{cat}}$ was reduced by a factor of around 10. For CSN-E59A, the activity on the polymer was only barely affected by the substitution, such that when hydrolyzing the polymer,

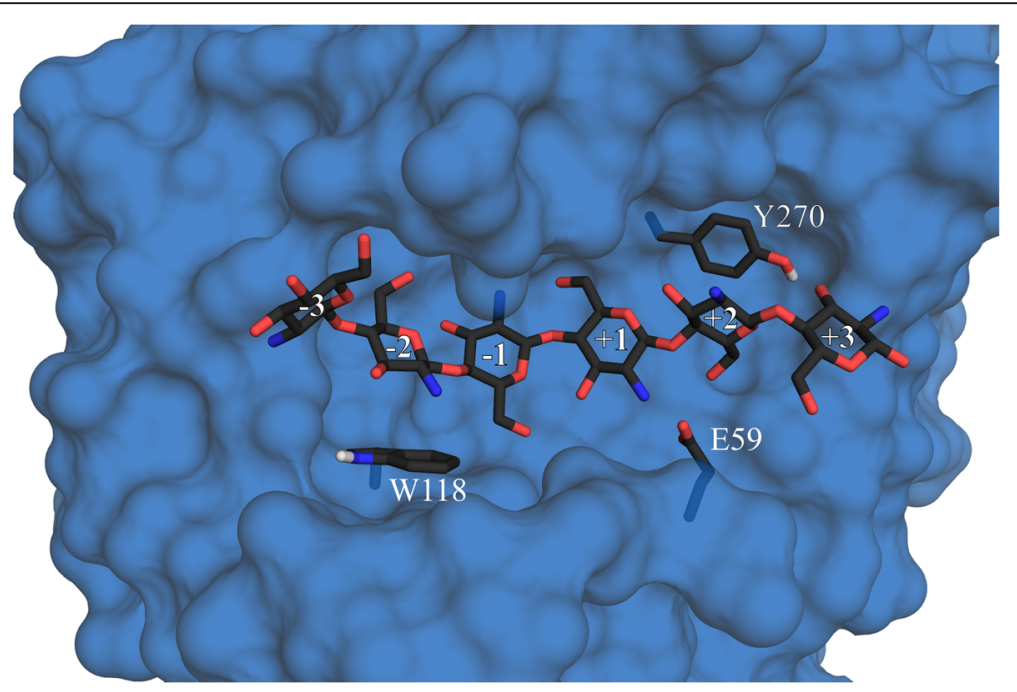

Fig. 1 Selected CSN residues with a putative function in substrate binding. A three-dimensional homology-based model of CSN based on the crystal structure of Bacillus sp. K17 chitosanase (PDB: 1V5C, amino acid sequence identity: 97.47\%), illustrating the side chain positions of the amino acids W1 18, E59, and Y270 relative to the docked substrate $D_{6}$. The subsites $(-3)$ to $(+3)$ are indicated. The enzyme surface without the side chains of the listed amino acids is pictured in blue, the labeled amino acid side chains emerging from the surface and $D_{6}$ are colored by element. 


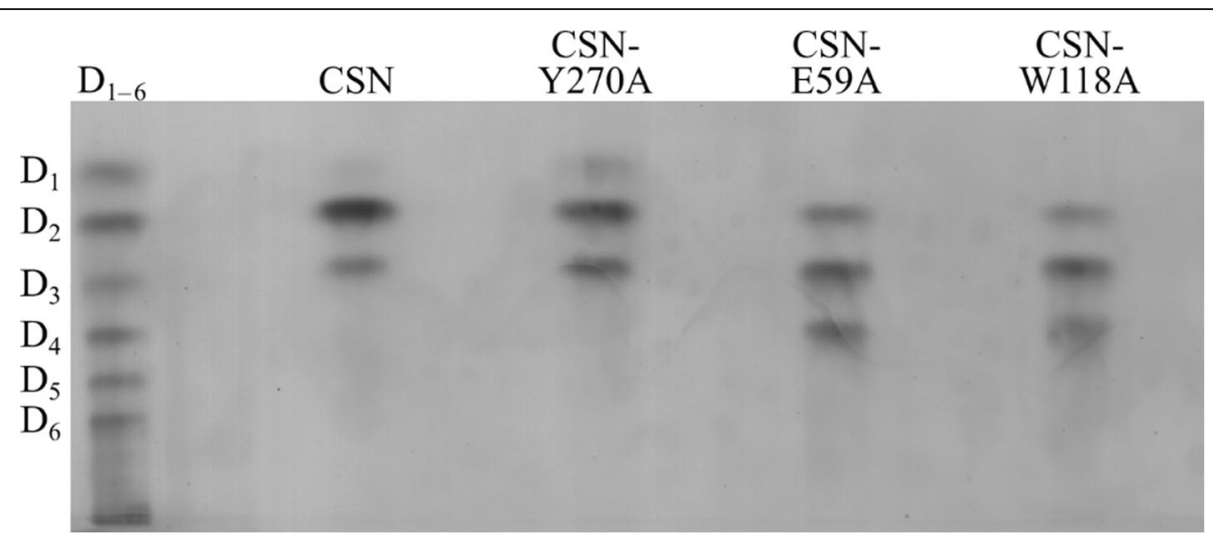

Fig. 2 Hydrolysates of CSN, CSN-Y270A, CSN-E59A, and CSN-W118A with chitosan polymer DA 1.5\% as a substrate. Hydrolysates were produced by incubating $1 \mathrm{mg} / \mathrm{ml}$ chitosan polymer DA $1.5 \%$ and each enzyme $(0.05 \mu \mathrm{M}$ of CSN, $0.42 \mu \mathrm{M}$ of CSN-Y270A, $0.05 \mu \mathrm{M}$ of CSN-E59A, and $2.5 \mu \mathrm{M}$ of CSN-W118A) for $16 \mathrm{~h}$ at $37^{\circ} \mathrm{C}$ and then used for a TLC. A mixture of $\mathrm{D}_{1-6}$ was utilized as a standard

this mutein retained about $87 \%$ of the maximum reaction velocity of CSN. However, CSN-E59A did have a drastically reduced activity on $\mathrm{D}_{4}$; compared to the $\mathrm{k}_{\text {cat }}$ of CSN on $\mathrm{D}_{4}$, the $\mathrm{k}_{\text {cat }}$ of CSN-E59A on $\mathrm{D}_{4}$ was nearly 10 times lower, and it was only about $1 \%$ of the $\mathrm{k}_{\text {cat }}$ for CSN-E59A on the chitosan polymer (Fig. 3d). Mutein CSN-W118A did show an almost 200 -fold decrease in activity on the polymer compared to CSN, but its hydrolytic efficiency on $\mathrm{D}_{4}$ was far lower or possibly even abolished entirely, as no a Chitosan polymer

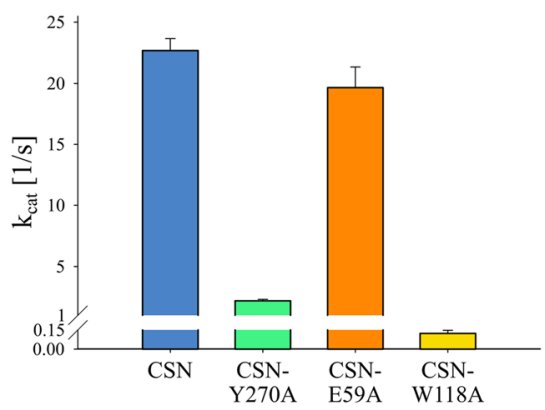

c $\quad \mathrm{D}_{5}$

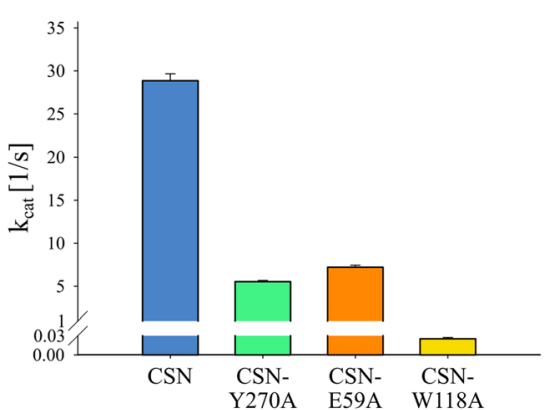

b $\quad \mathrm{D}_{4}$

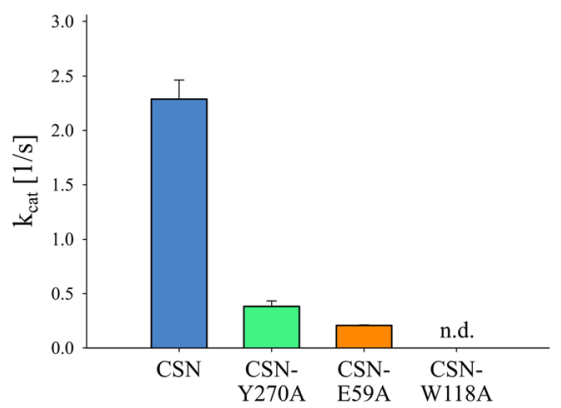

d Chitosan polymer and $\mathrm{D}_{4}$

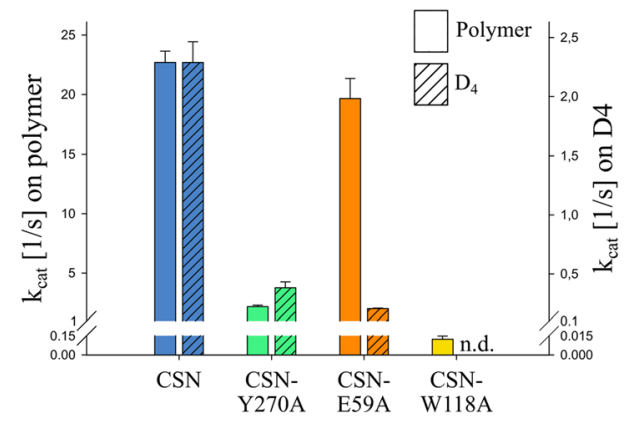

Fig. 3 Kinetic parameters of CSN, CSN-Y270A, CSN-E59A, and CSN-W118A on different substrates. The catalytic rate constant $\mathrm{k}_{\text {cat }}$ at $30^{\circ} \mathrm{C}$ is illustrated for the substrates (a) chitosan polymer DA 1.5\%, (b) $\mathrm{D}_{4}$, and (c) $\mathrm{D}_{5}$. Also, (d) a direct comparison between chitosan polymer DA 1.5\% and $\mathrm{D}_{4}$ is given. Three independent enzyme batches were used for each enzyme, and the kinetics were performed as triplicates for each batch. Data given are the mean values of all nine replicates, and the standard deviations between the three independent enzyme batches are indicated. A 30 min incubation period was used for CSN-E59A for $D_{4}$ and for CSN-W118A. All other reactions were incubated for 10 min. Different enzyme

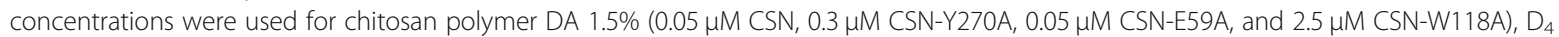
$(0.04 \mu \mathrm{M}$ CSN, $0.023 \mu \mathrm{M}$ CSN-Y270A, and $0.1 \mu \mathrm{M}$ CSN-E59A), and D $(0.02 \mu \mathrm{M}$ CSN, $0.168 \mu \mathrm{M}$ CSN-Y270A, $0.2 \mu \mathrm{M}$ CSN-E59A, and $1 \mu \mathrm{M}$ CSN-W118A) 
activity was detectable, and no kinetics could be determined as a result.

When comparing the catalytic rate constants between the substrates $D_{4}$ and $D_{5}$, all enzymes were multiple times more active when the additional fifth subsite was occupied during substrate binding. CSN and CSN-Y270A showed 12.6-fold and 14.5-fold higher $\mathrm{k}_{\mathrm{cat}}$ values, respectively, for $\mathrm{D}_{5}$ over $\mathrm{D}_{4}$, and CSN-E59A showed an even more drastic effect, with a 34.8-fold increase for $\mathrm{D}_{5}$ over $\mathrm{D}_{4}$. For CSN-W118A, which showed no activity at all on $\mathrm{D}_{4}$, the hydrolysis of $\mathrm{D}_{5}$ did occur, albeit only very slowly.

\section{In-depth characterization of substrate binding with deacetylated substrates}

We successfully generated muteins unable to efficiently hydrolyze $\mathrm{D}_{4}$ (CSN-E59A and CSN-W118A), but the results did not allow us to determine how the occupation of a fifth subsite mediated more stable substrate binding. To investigate this and to analyze why CSN-Y270A produced a different oligomer composition than the other two muteins, we performed ${ }^{18} \mathrm{O}$-labeling of the reducing ends of these oligomers. As substrates, we used $\mathrm{D}_{4}$ and $\mathrm{D}_{5}$ with an ${ }^{18} \mathrm{O}$ atom instead of a ${ }^{16} \mathrm{O}$ atom incorporated at the reducing end, and the resulting labeled and non-labeled products were measured via UHPLC-ELSD-ESI-MS ${ }^{1}$ to determine the substrate positioning during hydrolysis (Fig. 4). Since $\mathrm{D}_{1}$ ionizes very poorly with the experimental setup used, the amounts of the monomer (faded bars in Fig. 4) were not derived from quantification with external standards, but they were instead deduced from the quantified remaining products.

As expected, the main products produced by CSN from $\mathrm{D}_{4}$ were labeled and non-labeled $\mathrm{D}_{2}$ resulting from positioning the substrate within subsites $(-2)$ to $(+2)$. The slightly differing amounts can be explained by some of the produced oligomers losing their ${ }^{18} \mathrm{O}$ label during the incubation. Mutein CSN-Y270A showed different results for $\mathrm{D}_{4}$, such that the $\mathrm{D}_{4}$ substrate most frequently shifted its positioning to subsites $(-3)$ to $(+1)$, resulting in the production of labeled $D_{1}$ and non-labeled $D_{3}$. This shift was to some extent also visible when using $D_{5}$ as a substrate: While CSN and CSN-Y270A both mainly positioned the oligomer from subsites $(-3)$ to $(+2)$, the mutein also produced non-labeled $\mathrm{D}_{4}$ and, presumably, labeled $\mathrm{D}_{1}$ which occurred when the substrate occupied subsites $(-3)$ to $(+1)$ while leaving the unit at the non-reducing end unbound. For CSN-E59A and CSN-W118A, both muteins bound the $\mathrm{D}_{5}$ substrate from subsite $(-3)$ to subsite $(+2)$, as was seen for CSN.

Hydrolysis of low DA chitosan polymer resulted in the accumulation of $\mathrm{D}_{4}$ for both CSN-E59A and CSN-W118A. Therefore, this process, combined with a purification of the oligomers using size-exclusion chromatography, should allow for efficient production of $\mathrm{D}_{4}$.
Both muteins were tested for this purpose at a semitechnical scale with $1 \mathrm{~g}$ of chitosan polymer DA $1.5 \%$ as a substrate. The production was found to be possible with both muteins, but it was easier to handle and more efficient with CSN-W118A (Fig. 5). The incubation times were $21 \mathrm{~h}$ and $52 \mathrm{~h}$ for CSN-E59A and CSN-W118A, respectively, but only $136 \mathrm{mg}$ of $\mathrm{D}_{4}$ were purified from the CSN-E59A hydrolysate as compared to more than 400 $\mathrm{mg}$ of $\mathrm{D}_{4}$, which was virtually free of other reducing sugars, for CSN-W118A.

\section{Subsite specificities and preferences}

Using completely deacetylated substrates, distinct differences in the catalytic turnover rate and the substrate positioning were found between CSN and the muteins. In a second step, we compared the more complex and potentially bioactive paCOS product mixtures with higher DP and DA derived from incubating a medium DA substrate with the enzymes. To investigate if the amino acid substitutions changed the subsite specificities of the chitosanase, chitosan polymer DA 30\% was hydrolyzed to the endpoint, and the composition of the emerging oligomers was analyzed via quantitative mass spectrometric sequencing (Fig. 6). The subsites $(-3)$ to $(+3)$ were included in the experiments. No drastic differences between CSN and the tested muteins were found, but slight changes were observed. CSN's known absolute specificity for GlcN at subsites $(-2)$ and $(-1)$ and a general preference for GlcN units [22] were determined for all muteins under the conditions tested. Nonetheless, CSN-E59A and CSN-W118A showed a reduced tolerance for the presence of a GlcNAc unit in the substrate at subsite $(+2)$, and for both CSN-Y270A and CSN-W118A, subsite $(+1)$ was occupied with a GlcN unit more frequently than in the wildtype CSN; CSN-W118A showed an increased tolerance for GlcNAc at subsites $(-3)$ and, less marked, $(+3)$.

Since only minor differences were seen for the GlcN and GlcNAc frequencies in the chitosan polymer DA $30 \%$ hydrolysates produced with CSN and the muteins, we next analyzed the data for oligomers with the same DP and DA but different PAs in more detail. The oligomers chosen for this comparison were the monoacetylated tetramers $\mathrm{A}_{1} \mathrm{D}_{3}$. These paCOS were quite abundant, as they constituted ca. $10 \%(\mathrm{w} / \mathrm{w})$ of the hydrolysates (Additional file 1: Figure S2). All four possible PAs were seen for CSN, but by far the most abundant was ADDD, with the GlcNAc unit at the non-reducing end (Fig. 7). The second most frequent PA was DADD, followed by DDAD; only trace amounts of the oligomer DDDA were detectable. Altered ratios for the different PAs were found between CSN and the tested muteins. In contrast to CSN, the most common PA of $\mathrm{A}_{1} \mathrm{D}_{3}$ observed for CSN-Y270A and CSN-W118A was DADD, 


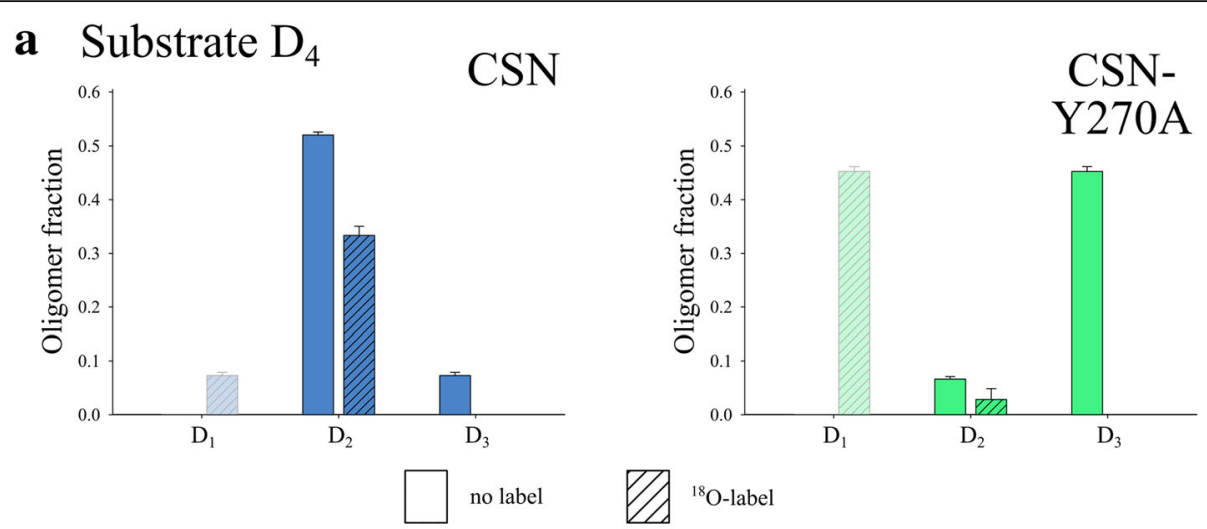

b Substrate $\mathrm{D}_{5}$
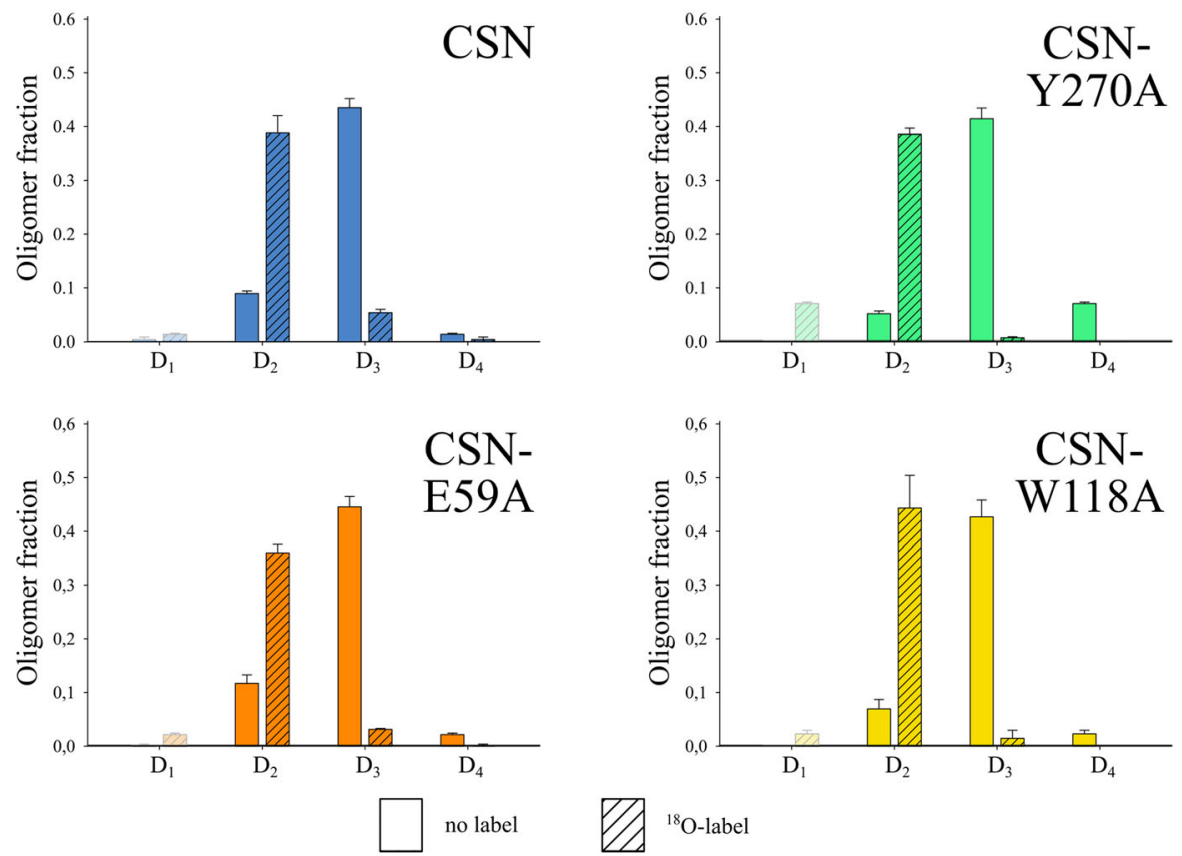

Fig. 4 Cleavage position when digesting (a) D4 and (b) D5 with CSN, CSN-Y270A, CSN-E59A, and CSN-W118A. The enzymes were incubated with $1 \mathrm{mM}$ of ${ }^{18} \mathrm{O}$-labeled $\mathrm{D}_{4}$ or $\mathrm{D}_{5}$ at $30^{\circ} \mathrm{C}$ for $10 \mathrm{~min}$ and the products were immediately measured using UHPLC-ELSD-ESI-MS ${ }^{1}$. The enzyme concentrations when using $D_{4}$ were $0.02 \mu \mathrm{M}$ for CSN and $0.035 \mu \mathrm{M}$ for CSN-Y270A. When using $D_{5}, 0.16 \mu \mathrm{M}$ of CSN, $0.42 \mu \mathrm{M}$ of CSN-Y270A, $0.33 \mu \mathrm{M}$ of CSN-E59A, and $5 \mu \mathrm{M}$ of CSN-W118A were applied. Quantification of the oligomers with and without the label at the reducing end was done by comparison with external oligomer standards. The amounts of $D_{1}$ (faded bars) were not determined by quantification of $D_{1}$ but instead deduced from the measured amounts of $D_{3}$ or $D_{4}$. The combined amount of all oligomers was set to 1 for each of the enzymes. Three independent enzyme batches were used for each enzyme, and the experiments were performed as triplicates for each batch. Data given are the mean values of all nine replicates and the standard deviations between the three independent enzyme batches are indicated

the difference being most striking for CSN-W118A which produced almost no ADDD. Conversely, CSN-E59A produced even more ADDD than CSN, such that ADDD made up ca. $80 \%$ of the $\mathrm{A}_{1} \mathrm{D}_{3}$ in its hydrolysis products. Overall, the slight differences in the preferences for GlcN and the tolerance for GlcNAc at certain subsites found between CSN and the muteins led to more distinct differences in the PAs of the resulting monoacetylated $A_{1} D_{3}$ tetramers.

\section{Discussion}

Our concept of performing mutagenesis on CSN to abolish its ability to efficiently hydrolyze $\mathrm{D}_{4}$ by targeting specific residues involved in substrate binding was successful for muteins CSN-E59A and CSN-W118A. These two muteins had no or very low activity on the fully deacetylated tetramer (Fig. 3), illustrating that we were able to increase the minimum DP that CSN can efficiently cleave from 4 to 5 . The remarkably small loss of activity 


\section{a Hydrolysate}

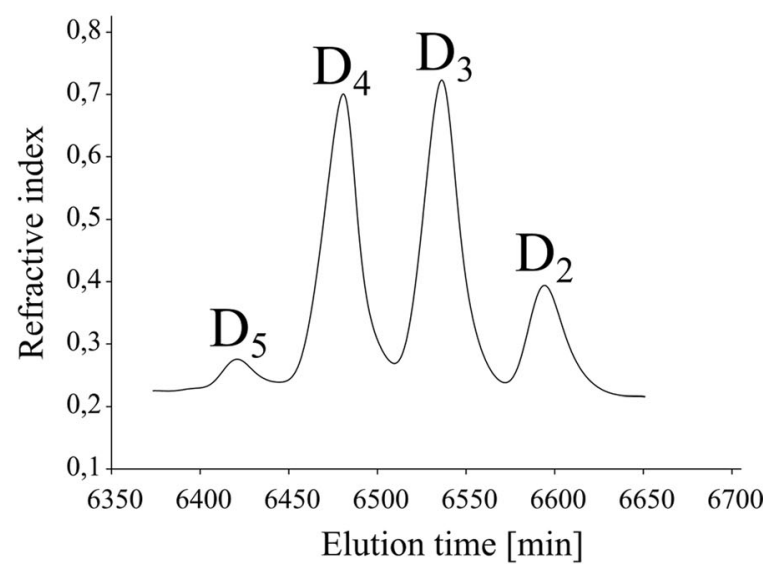

b $\quad \mathrm{D}_{4}$ after purification

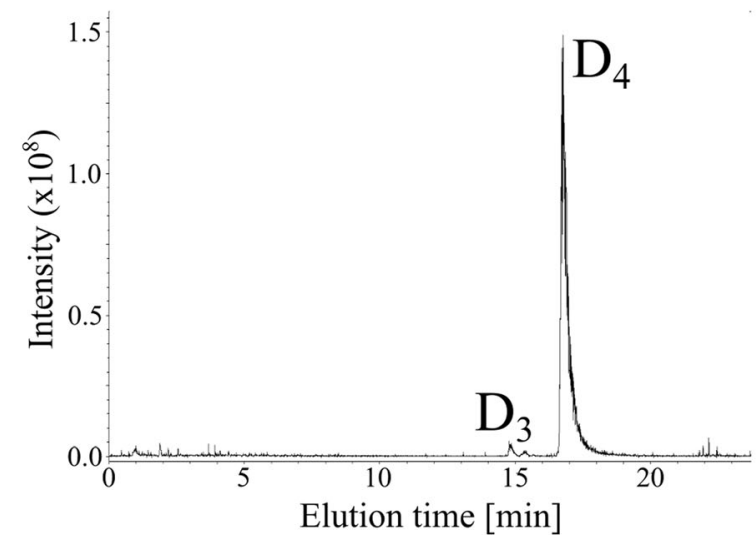

Fig. 5 Production of $D_{4}$ with CSN-W118A at a semitechnical scale. One $\mathrm{g}$ of chitosan polymer DA $1.5 \%$ was hydrolyzed with $0.367 \mu \mathrm{M}$ of CSN-W118A for $51.5 \mathrm{~h}$ at $37^{\circ} \mathrm{C}$. a A part of the elution profile for the separation of the chitosan oligomers by SEC. The products were identified using UHPLC-ESI-MS ${ }^{1}$ measurements. Fractions containing $\mathrm{D}_{4}$ were combined and washed, and the amount and purity of the product were determined by (b)

UHPLC-ELSD-ESI-MS ${ }^{1}$ measurements

that CSN-E59A showed toward the polymer indicates that the predicted role of E59 in substrate recognition at subsites $(+1)$ and $(+2)$ [36] is less relevant when more subsites are occupied. This may be because at the same subsites, other residues such as F365 and N271 (Additional file 1: Figure S3) likely also interact with the substrate, so that binding and hydrolysis of $\mathrm{D}_{4}$ can still occur, albeit at a very low rate; these residues have been implicated in such binding in docking studies [34]. Unlike E59, W118 seems to be indispensable for enzyme-substrate interaction at subsite $(-2)$. This was demonstrated by the mutein's non-detectable activity on $\mathrm{D}_{4}$ and simultaneously low $\mathrm{k}_{\text {cat }}$ values on both $\mathrm{D}_{5}$ and the DA $1.5 \%$ chitosan polymer.
The results also allowed for detailed insights into the magnitude of the substrate interactions at the different subsites relative to each other. We predicted that the impaired substrate binding at the mutated subsites would be compensated for when longer substrates were introduced because the oligomers would be able to occupy an additional fifth subsite, thereby allowing the substrate to form the correct "V-shape" conformation. This expected compensation was confirmed by the observations that CSN-E59A showed a stronger increase in activity than CSN when comparing the $\mathrm{k}_{\text {cat }}$ values on $\mathrm{D}_{4}$ and $\mathrm{D}_{5}$ and that CSN-W118A had detectable hydrolytic activity on $\mathrm{D}_{5}$ but not $\mathrm{D}_{4}$ (Fig. 3). For both CSN-E59A and CSN-W118A, the binding of $\mathrm{D}_{5}$ involved subsites $(-2)$ to $(+2)$ but it also involved the fifth subsite, (-3) (Fig. 4). This was contrary to the initial prediction for CSN-E59A and indicates that CSN much more strongly interacts with the substrate at subsite $(-3)$ than at subsite $(+3)$, which was virtually never occupied when binding $\mathrm{D}_{5}$ (Additional file 1: Figure S4).

Moreover, CSN-Y270A showed an unexpected shift in substrate positioning towards the minus subsites when binding $\mathrm{D}_{5}$, but especially when binding $\mathrm{D}_{4}$ (observed via ${ }^{18}$ O-labeled substrates). The resulting generation of $\mathrm{D}_{1}$ was highly uncommon for an endo-acting chitosanase (EC 3.2.1.132), but it has been reported before for a few fungal enzymes $[37,38]$. This shift indicates that the loss-of-function mutation on Y270 cannot be fully compensated for by other residues at this subsite. When only binding four GlcN units, positioning the substrate at subsites $(-3)$ to $(+1)$ is energetically more favorable than positioning them at subsites $(-2)$ to $(+2)$, since it allows the enzyme to interact using four subsites that are not directly affected by the mutation. This observation additionally highlights that stronger interactions occur at subsite $(-3)$ as compared to subsite $(+3)$. One residue that is predicted to predominantly contribute to these strong interactions at subsite $(-3)$ is W187, which forms stacking interactions [34] (Additional file 1: Figure S3).

Interestingly, positioning of the $\mathrm{D}_{4}$ substrate was not shifted for the other two muteins. In CSN-W118A, the mutation at subsite $(-2)$ might have shifted $\mathrm{D}_{4}$ binding to subsites $(-1)$ to $(+3)$. The reason this shift did not happen is likely because the relatively weak interactions at subsite $(+3)$ prevented any shift of $\mathrm{D}_{4}$ towards the plus subsites from being more energetically favorable. In the case of CSN-E59A, the original E59 residue likely helps the substrate take the "V-shape" conformation by creating two hydrogen bonds with the amino group of GlcN unit at subsite $(+1)$ and the C6-hydroxy group at subsite $(+2)$ [36]; therefore, mutating this residue would still impair binding at subsite $(+1)$, even if $\mathrm{D}_{4}$ shifted to subsites $(-3)$ to $(+1)$. 


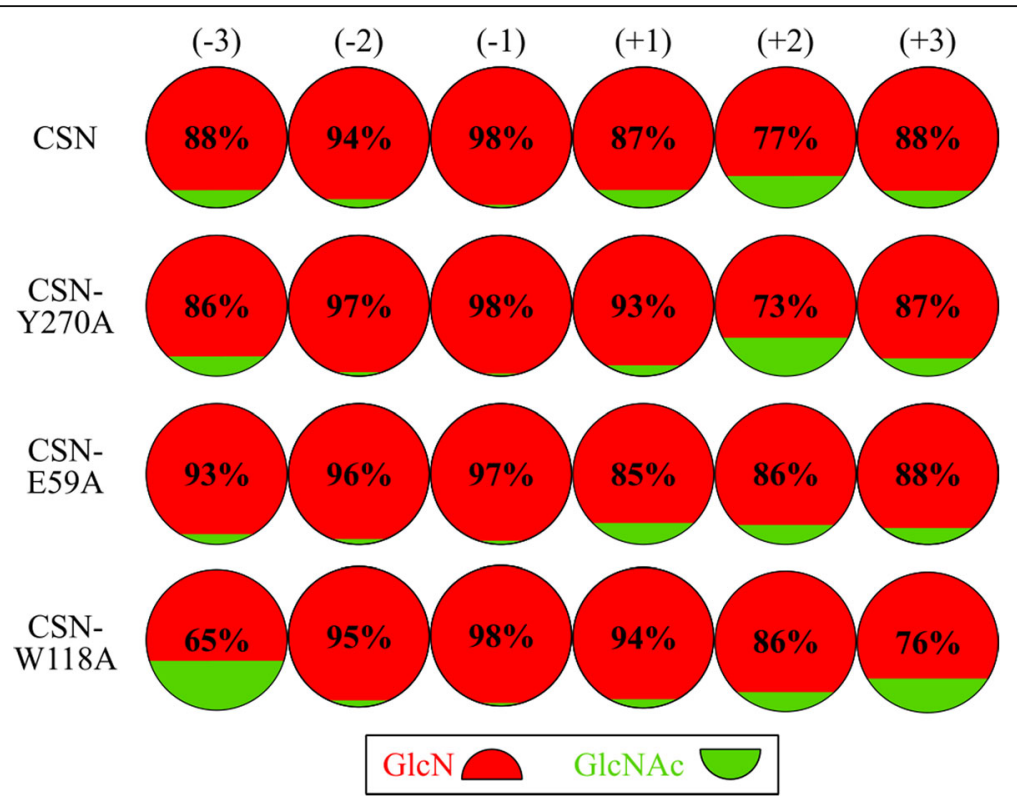

Fig. 6 Subsite specificities and preferences of CSN, CSN-Y270A, CSN-E59A, and CSN-W118A on chitosan polymer DA 30\%. The enzymes were incubated at $37^{\circ} \mathrm{C}$ with $1 \mathrm{mg} / \mathrm{ml}$ chitosan polymer DA 30\% until the endpoint (60 h in total). CSN, CSN-Y270A, CSN-E59A, and CSN-W118A were used at concentrations of $0.05 \mu \mathrm{M}, 0.3 \mu \mathrm{M}, 0.05 \mu \mathrm{M}$, and $2.5 \mu \mathrm{M}$, respectively. The frequencies of GlcN and GlcNAc units occurring at and near the reducing and non-reducing ends of the oligomers produced were determined using quantitative mass spectrometric sequencing. The mean values for the GlcN frequencies at the subsites $(-3)$ to $(+3)$ are indicated. The experiments were performed as triplicates with one batch of each enzyme

One practical application for the generated muteins CSN-E59A and CSN-W118A is that they can be utilized in a simple batch process to produce $\mathrm{D}_{4}$ in abundance (Fig. 5); the resulting $\mathrm{D}_{4}$ can be used as a substrate for the production of pure, fully defined paCOS tetramers using chitin deacetylases in reverse catalysis [18]. The fully acetylated tetramer $\mathrm{A}_{4}$ was recently shown to modulate the expression of genes involved in development, vegetative growth, and carbon and nitrogen metabolism in Arabidopsis thaliana [39], but tetrameric

\begin{tabular}{|c|c|c|c|c|}
\hline & & & & \\
\hline & & & & $\begin{array}{l}\text { ADDD } \\
\text { DADD } \\
\text { DDAD } \\
\text { DDDA }\end{array}$ \\
\hline $\mathbf{C S N}$ & $\mathbf{C S N - Y 2 7 0 A}$ & $\mathbf{C S N - E 5 9 A}$ & $\mathbf{C S N - W 1 1 8 A}$ & $\begin{array}{c}\mathbf{A}_{\mathbf{1}} \mathbf{D}_{\mathbf{3}} \\
\mathbf{p a t t e r n}\end{array}$ \\
\hline $\mathbf{5 7 . 8} \pm \mathbf{4 . 2} \%$ & $32.0 \pm 7.1 \%$ & $\mathbf{8 0 . 3} \pm \mathbf{0 . 7} \%$ & $5.9 \pm 2.7 \%$ & ADDD \\
\hline $28.3 \pm 7.0 \%$ & $\mathbf{6 0 . 6} \pm \mathbf{7 . 8} \%$ & $7.3 \pm 2.9 \%$ & $\mathbf{8 0 . 8} \pm \mathbf{7 . 9 \%}$ & DADD \\
\hline $11.5 \pm 3.0 \%$ & $6.0 \pm 0.1 \%$ & $9.8 \pm 2.6 \%$ & $12.5 \pm 5.1 \%$ & DDAD \\
\hline $2.3 \pm 0.1 \%$ & $1.4 \pm 0.1 \%$ & $2.6 \pm 0.1 \%$ & $0.8 \pm 0.6 \%$ & DDDA \\
\hline
\end{tabular}

Fig. 7 Differences in the pattern of acetylation between CSN, CSN-Y270A, CSN-E59A, and CSN-W118A for $A_{1} D_{3}$. The results are obtained from the reactions described in Fig. 6. The most prevalent monoacetylated tetramer product is indicated in bold for each enzyme. A combination of quantitative UHPLC-ELSD-ESI-MS ${ }^{1}$ and UHPLC-ELSD-ESI-MS ${ }^{2}$ measurements was used to determine the absolute amount of $A_{1} D_{3}$ in the hydrolysates and the relative frequency of each possible pattern. The experiments were performed as triplicates with one batch of each enzyme, the standard deviation is indicated 
paCOS were not yet tested. The ability to enzymatically produce all fourteen partially acetylated chitosan tetramers [18] in principle allows for the rigorous testing of the influence of PA on the bioactivities of paCOS, but rather large amounts of pure $\mathrm{D}_{4}$ and $\mathrm{A}_{4}$ are required to upscale tetrameric paCOS production. Establishing an efficient and easy means of producing $\mathrm{D}_{4}$, which can easily be converted into the fully acetylated chitin tetramer $\mathrm{A}_{4}$ using chemical $\mathrm{N}$-acetylation [40], represents a critical step in this endeavor.

While producing $\mathrm{D}_{4}$ using CSN-E59A was not particularly efficient, giving a yield of under $15 \%(w / w)$, CSN-W118A yielded more than $400 \mathrm{mg}$ of $\mathrm{D}_{4}$ from $1 \mathrm{~g}$ of chitosan polymer, and the $\mathrm{D}_{4}$ was virtually free of other reducing sugars. While we had to use a higher concentration of CSN-W118A compared to CSN-E59A, the former was clearly more suitable for efficient production of $\mathrm{D}_{4}$. Using a different approach for engineering, Regel et al. recently published the generation of a mutein of CSN named CSN-VRE which exhibited a strongly altered subsite specificity [35]. This enzyme could be utilized to produce oligomer mixtures containing $\mathrm{D}_{4}$ as well, but a production of pure $\mathrm{D}_{4}$ at a larger scale was not demonstrated. Moreover, CSN-VRE showed a drastically lower catalytic efficiency compared to the newly generated CSN-W118A; in fact, the activity of CSN-VRE on low DA chitosan polymer was reduced by a factor of over 1100 compared to the activity of non-mutated CSN. Clearly, efficient large-scale production of pure $\mathrm{D}_{4}$ for downstream applications is best achieved using the new mutein CSN-W118A. Applying enzyme engineering allowed the production of $D_{4}$ from low DA chitosan polymer as one of the main products in a batch process. The general approach for engineering CSN could potentially also be applied for enzymes from other glycoside hydrolase (GH) families if their active center residues are well-studied.

Single, pure fully defined chitosan oligomers such as the ones that can be produced using chitin deacetylases acting on, e.g., $\mathrm{D}_{4}$ or $\mathrm{A}_{4}$, bear a great potential when it comes to understanding the specific bioactivities of partially acetylated chitosans and deciphering their structure-function relationships. However, a large-scale application of single paCOS, e.g., in agriculture, is impractical because purifying them would be much too costly and time consuming. Instead, well-defined mixtures of paCOS containing the target oligomer(s) in known concentrations and being devoid of potentially inhibiting oligomers $[9,16]$ could be produced in a single step using chitosanases. To test whether the newly generated muteins are potentially suitable for such an approach, we analyzed hydrolysates produced using them for differences in their composition compared to those produced with CSN. The subsite specificities and preferences of CSN and its muteins, which directly affect the composition of the paCOS mixtures produced by them, were compared using chitosan polymer DA 30\% as a substrate. Because chitosanases typically have strong preferences for GlcN units, the average DP of hydrolysates produced from medium DA chitosans is larger than the DP of those produced from low DA chitosan; importantly, both increased oligomer length and partial acetylation are frequently associated with stronger bioactivities towards plants. In this context, it was previously shown that to elicit paCOS-induced defense reactions in Arabidopsis thaliana associated with an oxidative burst, the paCOS must have a DP of six or higher and at least four GlcNAc units [16]. While the overall composition of oligomeric products concerning their DP and DA was rather similar for the wildtype and mutein enzymes, we found striking differences in their PA. Whether or not these changes will influence bioactivities will be the subject of further studies.

Both the CSN wildtype and its muteins belong to the same class of chitosanases (former class III or current class A), with an absolute specificity for GlcN at subsites $(-2)$ and $(-1)$ (Fig. 6). Also, only slight differences were detected between CSN and the muteins regarding subunit preferences at any of the subsites ranging from $(-3)$ to $(+3)$. However, only a single DA substrate and a late time point were tested in this study, while a full assessment of subsite specificities and preferences requires testing of multiple conditions [22].

Nevertheless, in spite of these minor differences in subsite preferences, we found distinct differences in the paCOS produced, particularly in their PA (Fig. 7), which might result in altered bioactivities of the hydrolysates. These structural differences were exemplified by the sequences of the monoacetylated tetramers $A_{1} D_{3}$, since these were present in all the hydrolysates and showed clear differences between the three muteins. Especially interesting in this context are CSN-E59A and CSN-W118A, since they almost exclusively produced ADDD or DADD, respectively. These differences between CSN and the muteins can be explained based on the mutations. The increased production of ADDD that was observed for CSN-E59A requires more frequent binding of an acetylated GlcNAc unit at the subsite $(+1)$ (Fig. 8). Such an event is less likely to occur in CSN due to the predicted interaction of the negatively charged E59 with the positively charged amino group of a GlcN unit bound at subsite $(+1)$ [36]. The substitution of E59 for alanine in CSN-E59A eliminates this effect, facilitating binding of a GlcNAc residue at subsite $(+1)$. For both CSN-Y270A and CSN-W118A, more DADD was produced, as a result of a GlcNAc unit positioned at subsite $(+2)$ or $(-3)$ during cleavage (Fig. 8$)$. The substitution of Y270 for the smaller alanine widens the 


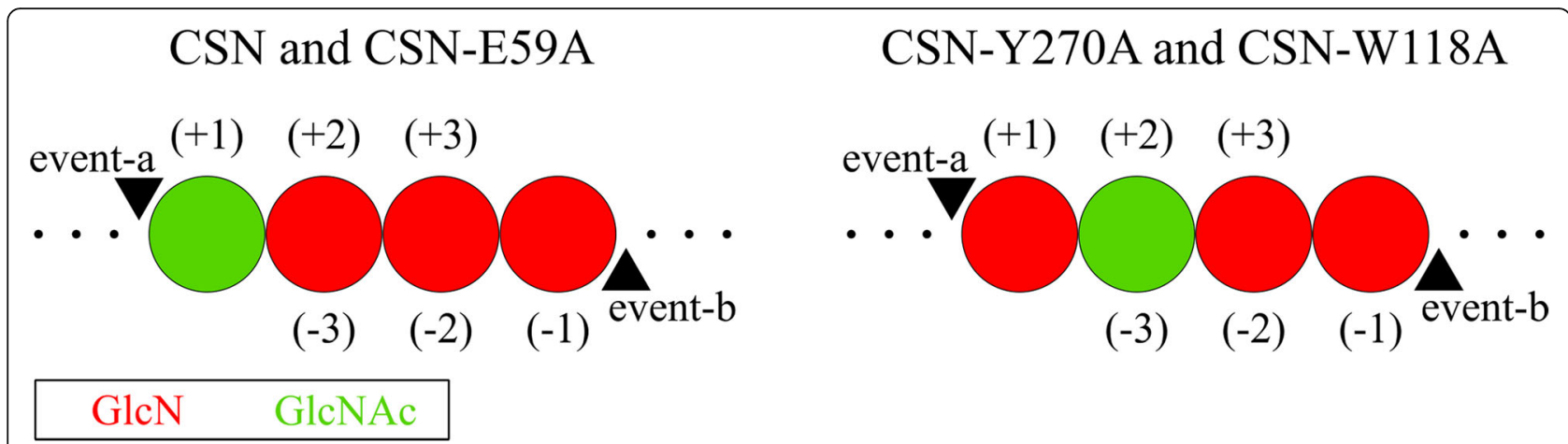

Fig. 8 Visualization of the cleavage events $a$ and $b$ to produce $A_{1} D_{3}$. Pictured here are the most common $P A$ of $A_{1} D_{3}$ found in the hydrolysates produced with CSN, CSN-Y270A, CSN-E59A, and CSN-W118A from Fig. 7. The positioning of the GlCN/GlCNAc units at the different subsites is shown. Also indicated by black triangles are the positions at which the two cleavage events must have occurred to produce the oligomer

enzymatic cleft at the subsite $(+2)$, allowing accommodation for the larger GlcNAc unit and facilitating its binding. The substitution of W118 for alanine could allow the D131 side chain located in close proximity to W118 at subsite $(-3)$ (Additional file 1: Figure S3) to move towards the space previously occupied by W118, which in CSN is predicted to form a stable hydrogen bond with the substrate [34]. As a result of replacing W118, steric hindrance at subsite $(-3)$ might no longer occur, and a GlcNAc unit might be more easily accepted there.

\section{Conclusion}

In this work, rational protein engineering was used to generate three muteins of CSN from Bacillus sp. MN by impairing or abolishing stable substrate binding at specific subsites of the active center. The goals were twofold: First, we intended to increase from 4 to 5 the minimum DP CSN can cleave, thus allowing for the effective production of the fully deacetylated tetramer $D_{4}$ in a batch process; second, we aimed to enable the generation of new hydrolysates with altered composition and, consequently, potentially altered bioactivities. Both goals were successfully achieved. CSN-E59A and CSN-W118A both showed reduced or missing activity on the tetramer compared to the wildtype enzyme. CSN-W118A was used to efficiently generate $\mathrm{D}_{4}$ from a chitosan polymer with very low DA, which was then purified to virtual homogeneity by size-exclusion chromatography. This tetramer, and the fully acetylated chitin tetramer $\mathrm{A}_{4}$ which can easily be produced from $\mathrm{D}_{4}$ using chemical $\mathrm{N}$-acetylation, can now be used as a substrate for the generation of fully defined partially acetylated tetrameric COS using chitin deacetylases. Even though the subsite preferences of the three muteins were only slightly different from CSN, distinct differences in the PA of the paCOS products were found, showing that engineered chitosanases can yield novel paCOS mixtures potentially containing oligomers with specific bioactivities. Furthermore, a shifted substrate positioning in the active center of CSN-Y270A compared to the wildtype revealed that not all subsites are equally significant for substrate binding; such knowledge about the strength of the molecular interactions with the substrate at individual subsites can be valuable for further protein engineering.

\section{Methods}

All chemicals were of analytical grade and purchased from Sigma-Aldrich (München, Germany) or Roth (Karlsruhe, Germany).

\section{Chitosans and COS}

Chitosan polymer with DA 1.5\%, DP 1300, and dispersity $Ð$ of 1.8 (kindly provided by Mahtani Chitosan Pvt. Ltd., Veraval, India) was used directly or as the starting material for the preparation of chitosan polymer DA 30\% by partial chemical $\mathrm{N}$-acetylation under homogenous conditions according to Vachoud et al. [41]. The DA of the resulting chitosan was verified using ${ }^{1} \mathrm{H}-\mathrm{NMR}$ in acidic $\mathrm{D}_{2} \mathrm{O}$ at $\mathrm{pD}$ 3-4 [42]. DP and $Ð$ were verified using high-performance size-exclusion chromatography (HP-SEC) with a differential refractometer and multi-angle laser light scattering [43]. Chitin and chitosan oligomers were either purchased from Carbosynth (Compton, UK) or produced enzymatically by hydrolysis of chitosan polymer DA $1.5 \%$ followed by separation through semi-preparative size-exclusion chromatography (SEC) (see section 1.7.1010) and mass spectrometric quantification (see section 1.7.8.2).

\section{Bacterial strains, vectors, and culture conditions}

Escherichia coli DH5 $\alpha$ was used as a host for recombinant plasmids, E. coli Rosetta 2 (DE3) [pLysSRARE2] (Merck KGaA, Darmstadt, Germany) was used for recombinant protein expression. The bacteria were incubated at $37{ }^{\circ} \mathrm{C}$ or $26^{\circ} \mathrm{C}$ on either LB agar (Roth, Karlsruhe, Germany) or at $120-180 \mathrm{rpm}$ in liquid LB 
medium (Roth, Karlsruhe, Germany) containing the appropriate antibiotics $(100 \mu \mathrm{g} / \mathrm{ml}$ ampicillin or $100 \mu \mathrm{g} / \mathrm{ml}$ ampicillin and $34 \mu \mathrm{g} / \mathrm{ml}$ chloramphenicol) for plasmid stability. Stocks for long term storage at $-80^{\circ} \mathrm{C}$ were prepared using $25 \%(v / v)$ glycerol and $0.5 x$ LB medium.

\section{Generation of mutein-coding plasmids}

The vector pET-22b(+)::StrepII-csn [33] was used as a template for the generation of all CSN muteins using a Rolling Circle PCR and subsequent ligation. Phusion Hot Start II High-Fidelity DNA Polymerase and T4 Rapid DNA Ligase (Fisher Scientific, Schwerte, Germany) were used according to the manufacturer's instructions. The primers E59Afw (5'-Pho-TCCTTTTACGTAATAACCA CCAGGTAAAG-3') and E59Arev (5'-Pho-GCGATTAC AGGTGATGCGGATGGG-3') were used to introduce the mutation of E59 to A, resulting in the vector pET-22b(+)::StrepII-csn-E59A. The primers Y270Afw (5'-Pho-ATAATATGCATTTGTATATTCTGACTC-3'), Y270Arev (5'-Pho-GCGAATGCTAGTCGAGTACCTTT A-3'), W118Afw (5'-Pho-TCCCATTAAATTAGGATTT TGAGAG-3') and W118Arev (5'-Pho-GCAGTTGTC GCAGATAGTAAAAAAGC-3') were used analogously to create pET-22b(+)::StrepII-csn-Y270A and pET-22b $(+):: S t r e p I I-c s n-W 118 A$. The finished vectors were used for the transformation of E. coli $\mathrm{DH} 5 \alpha$ as well as E. coli Rosetta 2 (DE3) [pLysSRARE2] and checked via sequencing. Primers were ordered from Eurofins MWG Operon (Eversberg, Germany). Sequencing was done by Microsynth Seqlab (Göttingen, Germany).

\section{Heterologous expression of CSN and the muteins}

E. coli Rosetta 2 containing one of the respective plasmids was cultivated in $500 \mathrm{ml} \mathrm{LB}$ medium supplemented with solution $\mathrm{M}\left(50 \mathrm{x}, 1.25 \mathrm{M} \quad \mathrm{NaH}_{2} \mathrm{PO}_{4}, 1.25 \mathrm{M}\right.$ $\mathrm{KH}_{2} \mathrm{PO}_{4}, 2.5 \mathrm{M} \mathrm{NH} \mathrm{Nl}_{4} \mathrm{Cl}, 0.25 \mathrm{M} \mathrm{Na}_{2} \mathrm{SO}_{4}$ ) and solution $5052(50 x, 25 \%[v / v]$ glycerol, $10 \%[w / v] \alpha$-lactose monohydrate, $2.5 \%[\mathrm{w} / \mathrm{v}] \mathrm{D}$-glucose) for autoinduction of the expression and antibiotics $(34 \mu \mathrm{g} / \mathrm{ml}$ chloramphenicol and $100 \mu \mathrm{g} / \mathrm{ml}$ ampicillin) [44]. Incubation was done at $26^{\circ} \mathrm{C}$ and $120 \mathrm{rpm}$ for $48 \mathrm{~h}$. Subsequent purification of the proteins was performed via Strep-tag II/Strep-Tactin affinity chromatography with $1 \mathrm{ml}$ Strep-Tactin columns (Qiagen, Hilden, Germany) according to Nampally et al. [33], and the protein concentrations were measured with a Pierce ${ }^{\text {tx }}$ BCA Protein Assay Kit (Fisher Scientific, Schwerte, Germany).

\section{SDS-PAGE and western blot}

All samples were denatured in loading buffer $(4 \mathrm{x}, 0.25 \mathrm{M}$ Tris/HCl pH 6.8, $8 \%[w / v]$ SDS, $20 \%$ [w/v] glycerol, $0.04 \%$ $[\mathrm{w} / \mathrm{v}]$ bromophenol blue, $0.4 \%[v / \mathrm{v}] \quad \beta$-mercaptoethanol) for $10 \mathrm{~min}$ at $90^{\circ} \mathrm{C}$. The samples, Precision Plus Protein ${ }^{\mathrm{mm}}$ All Blue Prestained standard (Bio-Rad Laboratories,
Hercules, USA), a $12.5 \%(\mathrm{w} / \mathrm{v})$ polyacrylamide gel, and the appropriate buffer $(0.025 \mathrm{M}$ Tris, $0.192 \mathrm{M}$ glycerol, $1 \%$ [w/ v] SDS) were then used for SDS-PAGE according to Laemmli [45]. After separation, the proteins were either used for Coomassie staining (45\% [v/v] methanol, 10\% [v/ v] acetic acid, $0.25 \%[\mathrm{w} / \mathrm{v}] \mathrm{CuSO}_{4}, 0.2 \%$ [w/v] Coomassie brilliant blue G250), or they were transferred to a nitrocellulose membrane (GE Healthcare Europe GmbH, Freiburg, Germany) using a semi-dry transfer procedure [46]. The membrane was incubated with $5 \%$ milk powder in TBS (10 mM Tris/ $\mathrm{HCl}$ and $150 \mathrm{mM} \mathrm{NaCl}, \mathrm{pH} 7.5)$ for $1 \mathrm{~h}$. A Strep-Tactin horseradish peroxidase conjugate (IBA, Göttingen, Germany) was used according to the manufacturer's instructions to detect all Strep-tag II fusion proteins.

Enzymatic hydrolysis of chitosan polymers and oligomers Sodium acetate buffer ( $40 \mathrm{mM}, \mathrm{pH} 6)$ was used for all enzymatic reactions and the temperature was controlled using a thermal mixer, except when producing $\mathrm{D}_{4}$ at a semitechnical scale. An incubation temperature of $37^{\circ} \mathrm{C}$ was chosen when extensive hydrolysis was desired; for brief incubation times, $30^{\circ} \mathrm{C}$ was used instead. Substrates were used at $1 \mathrm{mg} / \mathrm{ml}$ in the case of chitosan polymers and at $1 \mathrm{mM}$ for $\mathrm{D}_{4}$ and $\mathrm{D}_{5}$. Exceptions to this were the enzymatic reactions to produce $\mathrm{D}_{4}$ at a semitechnical scale and those to determine kinetics. Enzyme concentrations varied as suitable concentrations were either determined experimentally or they were chosen based on the enzymes' kinetic parameters. When preparing the samples for analysis by TLC, $0.05 \mu \mathrm{M}$ of CSN, $0.3 \mu \mathrm{M}$ of CSN-Y270A, $0.05 \mu \mathrm{M}$ of CSN-E59A, and $2.5 \mu \mathrm{M}$ of CSN-W118A were used and incubation was done at $37^{\circ} \mathrm{C}$ for $16 \mathrm{~h}$. The same enzyme concentrations were used when determining the subsite specificities of the enzymes. In this context, the hydrolysates were incubated at $37^{\circ} \mathrm{C}$ for $48 \mathrm{~h}$, then supplemented with an equal total amount of fresh enzyme and subsequently incubated for another $12 \mathrm{~h}$ to ensure that the end point of hydrolysis was reached, as verified via a reducing end assay (see section 1.7.7).

\section{Kinetics}

Kinetics were determined on chitosan polymer DA $1.5 \%$ as well as on oligomers $\mathrm{D}_{4}$ and $\mathrm{D}_{5}$ at $30^{\circ} \mathrm{C}$ using three independent batches of each enzyme and recording triplicates for each batch. The reaction velocities of the enzymes on the polymer were quantified using the reducing end assay (see section 1.7.7) to determine how many cleavage events occurred over time. The reactions were always incubated for $10 \mathrm{~min}$ (except for $30 \mathrm{~min}$ in the case of CSN-W118A) and the increase in reducing ends was determined between an early $\left(t_{0}\right)$ and a late timepoint $\left(t_{10} / t_{30}\right)$. The tested substrate concentrations 
ranged from $0.15-2.5 \mathrm{mg} / \mathrm{ml}$ chitosan polymer DA $1.5 \%$, and enzymes CSN, CSN-Y270A, CSN-E59A, and CSN-W118A were used at $0.05 \mu \mathrm{M}, 0.3 \mu \mathrm{M}, 0.05 \mu \mathrm{M}$, and $2.5 \mu \mathrm{M}$, respectively. A quantification of the enzymatic activity on $\mathrm{D}_{4}$ and $\mathrm{D}_{5}$ was achieved by using UHPLC-ELSD-ESI-MS ${ }^{1}$ measurements and external oligomer standards (see section 1.7.8.1) to determine the increase of the relevant oligomers between two different time points. The reaction velocities were linear for the chosen substrate concentrations, enzyme concentrations, and incubation times. $\mathrm{D}_{4}$ and $\mathrm{D}_{5}$ were used at $0.01-2$ $\mathrm{mM}$, the reaction time was set to $10 \mathrm{~min}$ (except for 30 min in the cases of CSN-E59A with $\mathrm{D}_{4}$ and CSN-W118A with $\mathrm{D}_{5}$ ), and the enzymes were used at concentrations of $0.04 \mu \mathrm{M}\left(\mathrm{CSN}\right.$ for $\left.\mathrm{D}_{4}\right), 0.02 \mu \mathrm{M}\left(\mathrm{CSN}\right.$ for $\left.\mathrm{D}_{5}\right), 0.023 \mu \mathrm{M}$ (CSN-Y270A for $\left.\mathrm{D}_{4}\right), 0.168 \mu \mathrm{M}\left(\mathrm{CSN}-\mathrm{Y} 270 \mathrm{~A}\right.$ for $\left.\mathrm{D}_{5}\right)$, $0.1 \mu \mathrm{M}$ (CSN-E59A for $\left.\mathrm{D}_{4}\right), 0.2 \mu \mathrm{M}$ (CSN-E59A for $\mathrm{D}_{5}$ ), and $1.0 \mu \mathrm{M}(\mathrm{CSN}-\mathrm{W} 118 \mathrm{~A})$. For further analysis, the program Origin 8 (OriginLab Corporation, USA) was used. The reaction velocities were plotted against the corresponding substrate concentrations and a Hill fit was applied to determine kinetic parameters. The number of reducing ends formed for $\mathrm{D}_{4}$ was calculated by adding the amount of $D_{2}$ divided by the factor 2 (cleavage of $D_{4}$ into $D_{2}$ and $D_{2}$ ) and the amount of $D_{3}$ (cleavage of $D_{4}$ into $D_{3}$ and $D_{1}$ ). When $D_{5}$ was used as the substrate, the amounts of $D_{2}$ and $D_{3}$ were added and halved (cleavage of $D_{5}$ into $D_{2}$ and $D_{3}$ ) and added to the amount of $D_{4}$ (cleavage of $D_{5}$ into $D_{1}$ and $D_{4}$ ). This was done under the assumption that any $\mathrm{D}_{4}$ formed from $\mathrm{D}_{5}$ would not be used as a substrate by the enzymes during the $10-30 \mathrm{~min}$ incubation time because $D_{5}$ would still be the predominant oligomer in the reactions and is a preferred substrate for all enzymes used.

\section{Determination of the cleavage position when digesting $D_{4}$ and $D_{5}$}

$\mathrm{D}_{4}$ and $\mathrm{D}_{5}$ were labeled with ${ }^{18} \mathrm{O}$ at the reducing end using $\mathrm{H}_{2}{ }^{18} \mathrm{O}$ (see section 1.7.8.2). Since the ${ }^{18} \mathrm{O}$ is gradually exchanged for ${ }^{16} \mathrm{O}$ once the substrates come into contact with $\mathrm{H}_{2}{ }^{16} \mathrm{O}$, the subsequent enzymatic reactions and UHPLC-ELSD-ESI-MS ${ }^{1}$ measurements were kept as brief as possible. The enzymes were used at different concentrations $\left(0.02 \mu \mathrm{M}\right.$ of CSN for $\mathrm{D}_{4}$ and $0.16 \mu \mathrm{M}$ for $\mathrm{D}_{5}, 0.035 \mu \mathrm{M}$ of CSN-Y270A for $\mathrm{D}_{4}$ and $0.42 \mu \mathrm{M}$ for $\mathrm{D}_{5}$, $0.33 \mu \mathrm{M}$ of CSN-E59A for $\mathrm{D}_{5}, 5 \mu \mathrm{M}$ of CSN-W118A for $\mathrm{D}_{5}$ ) and were incubated with the substrates for $10 \mathrm{~min}$ at $30^{\circ} \mathrm{C}$, immediately followed by the measurement. The oligomers were then quantified using external oligomer standards (see section 1.7.8.1).

\section{Production of $\mathrm{D}_{4}$ at a semitechnical scale}

One g of chitosan polymer DA $1.5 \%(5 \mathrm{mg} / \mathrm{ml})$ and the mutein CSN-W118A $(0.367 \mu \mathrm{M})$ were used to produce
$\mathrm{D}_{4}$ at a semitechnical scale. The enzyme was purified as described before, but without the use of TEA to avoid contamination of the product. The enzymatic reaction was performed in $2 \mathrm{mM}$ ammonium formiate buffer $\mathrm{pH}$ 5.5 and was stirred for $51.5 \mathrm{~h}$ at $37^{\circ} \mathrm{C}$. A water bath was used to control the temperature. During the reaction, the progress of the hydrolysis was monitored using UHPLC-ELSD-ESI-MS ${ }^{1}$-measurements. When almost no pentamer or larger oligomers were detectable anymore, the reaction was ended by freezing the solution. The $\mathrm{D}_{4}$ was separated from other oligomers using SEC and then quantified as well as checked for its purity using reducing end assay (see section 1.7.7) and ESI-MS ${ }^{1}$ with internal $\mathrm{R}^{*}$ standards (see section 1.7.8.2). Analogously, another $\mathrm{D}_{4}$ production procedure was performed using mutein CSN-E59A, but at a concentration of $0.2 \mu \mathrm{M}$, and the incubation time was limited to 20.66 h.

\section{Reducing end assay}

For the determination of kinetics on chitosan polymer DA $1.5 \%$, a reducing end assay as described by Horn and Eijsink [47] was used to quantify the newly formed reducing ends over time. The enzymatic reactions were stopped by adding $0.5 \mathrm{M} \mathrm{NaOH}$. The amount of reducing ends in the sample was determined by measuring the absorption at $620 \mathrm{~nm}$ with a Multiskan ${ }^{\circ} \mathrm{GO}$ microplate spectrophotometer (Fisher Scientific, Schwerte, Germany) and then comparing it to that of $D$-glucosamine standards $(0.05-1.5 \mathrm{mM})$.

\section{UHPLC-ELSD-ESI-MS ${ }^{\mathrm{n}}$ analysis}

Chitosan oligomers were separated using a Dionex Ultimate 3000RS UHPLC system (Thermo Fisher Scientific, Waltham, USA) coupled to an evaporative light scattering detector (Model Sedex 90LT, Sedere, Alfortville Cedex, France) and an ESI-MS ${ }^{\mathrm{n}}$-detector (amaZon speed, Bruker, Bremen, Germany). Separation of the oligomers was achieved by hydrophilic interaction liquid chromatography (HILIC) using an Acquity UHPLC BEH Amide column $(1.7 \mu \mathrm{m}, 2.1 \mathrm{~mm} \times 150 \mathrm{~mm}$; Waters Corporation, Milford, USA) in combination with a VanGuard pre-column $(1.7 \mu \mathrm{m}, 2.1 \mathrm{~mm} \times 5 \mathrm{~mm}$; Waters Corporation, Milford, USA). The samples were split between ELSD and ESI-MS ${ }^{\mathrm{n}}$ detectors using a 1:1 splitter (Accurate, Dionex Corporation, Sunnyvale, USA). All of the used UHPLC-ELSD-ESI-MS ${ }^{\mathrm{n}}$ methods were based on the ones described by Cord-Landwehr et al. [17]. The injection volume was always $1 \mu$ for undiluted samples and $2 \mu \mathrm{l}$ for samples that were diluted with equal parts of $0.5 \mathrm{M} \mathrm{NaOH}$ to stop an enzymatic reaction. Data Analysis 4.1 software (Bruker, Bremen, Germany) was used for analysis of the results. 


\section{Quantification of chitosan oligomers using external standards}

For determination of kinetics using $\mathrm{D}_{4}$ and $\mathrm{D}_{5}$ as well as for analysis of the substrate positioning of those oligomers, UHPLC-ELSD-ESI-MS ${ }^{1}$ methods (gradient elution profile in Additional file 1: Table S1) and external oligomer standards were used. Standards were measured using the same method and buffers as in the respective experiments using $\mathrm{D}_{2}, \mathrm{D}_{3}$, and $\mathrm{D}_{4}(0.001-1 \mathrm{mM})$. $\mathrm{D}_{1}$ was not measured since it ionizes very poorly using the described setup and the amounts of $D_{1}$ present in the samples were deduced from the measured amounts of the other oligomers.

\section{Quantitative sequencing}

For determination of the enzymes' subsite specificities, quantitative sequencing was used as described by Cord-Landwehr et al. [17]. The method involves quantitative UHPLC-ELSD-ESI-MS ${ }^{1}$ measurements for quantification of the oligomers and determination of DP and DA combined with UHPLC-ELSD-ESI-MS ${ }^{2}$ measurements to determine the pattern of acetylation. The oligomers in the produced hydrolysates were deutero$N$-acetylated with $\left[{ }^{2} \mathrm{H}_{6}\right]$-acetic anhydride (Sigma-Aldrich, St. Louis, USA). This caused oligomers with the same DP, but different DAs to elute at the same time and allowed the use of a single internal standard for each DP. As standards, $\mathrm{GlcN}_{2-6}$ oligomers were $N$-acetylated using $\left[{ }^{13} \mathrm{C}_{4},{ }^{2} \mathrm{H}_{6}\right]$-acetic anhydride (Sigma-Aldrich, St. Louis, USA); these are referred to as $\mathrm{R}_{2-6}^{*}$ standards. The deutero- $N$-acetylated samples and the $R^{*}{ }_{2-6}$ standards were mixed, dried in vacuo, and resolved in water and then, $2 \mu \mathrm{l}$ containing $2 \mu \mathrm{g}$ of the oligomers and 75 ng of each of the standards were analyzed via LC-MS ${ }^{1}$ (gradient elution profile in Additional file 1: Table S1). The target mass was changed over time, adjusting it to the eluting oligomers. This was done to optimize ion transmission and detection of the products. To allow quantitative pattern determination, the deuter$\mathrm{o}-\mathrm{N}$-acetylated hydrolysates were dried in vacuo and then labeled at the reducing ends with ${ }^{18} \mathrm{O}$ using $\mathrm{H}_{2}{ }^{18} \mathrm{O}$ (euriso-top, Saint-Aubin, France). One $\mu \mathrm{g}$ of each hydrolysate was then analyzed via LC-MS ${ }^{2}$ (gradient elution profile in Additional file 1: Table S1). The results of the $\mathrm{LC}_{-} \mathrm{MS}^{1}$ and $\mathrm{LC}-\mathrm{MS}^{2}$ measurements were then combined and evaluated according to Cord-Landwehr et al. [17].

\section{Thin layer chromatography (TLC)}

Silica plate high performance thin-layer chromatography (HP-TLC) was used to qualitatively analyze chitosan oligomers produced by enzymatic hydrolysis. Aliquots $(25 \mu \mathrm{g})$ of the oligomers in $10 \mu \mathrm{l} \mathrm{H}_{2} \mathrm{O}$ and a $\mathrm{GlcN}_{1-6}$ standard $(12 \mu \mathrm{g}$ of each oligomer) were sprayed on a
TLC plate coated with silica gel (Merck KGaA, Darmstadt, Germany) using an Automatic TLC sampler 4 (CAMAG, Switzerland). For the subsequent separation, a 5:4:2:1 $(v / \mathrm{v} / \mathrm{v} / \mathrm{v})$ mixture of $n$-butanol, methanol, $25 \%$ (v/v) ammonia, and $\mathrm{H}_{2} \mathrm{O}$ was used. The TLC plate was then briefly dipped into $30 \%(\mathrm{v} / \mathrm{v})$ ammonium bisulfate and heated using a hot air gun until the separated products were visible [48].

\section{Size-exclusion chromatography (SEC)}

Preparative separation of chitosan oligomers was achieved by size-exclusion chromatography using a SECcurity GPC System (PSS Polymer Standards Service, Mainz, Germany), three serial HiLoad 26/600 Superdex 30 prep grade columns (GE Healthcare Europe GmbH, Freiburg, Germany), and an Agilent 1200 series refractive index detector (Agilent Technologies, Santa Clara, USA). For data recording, the WinGPC UniChrom software (PSS Polymer Standards Service, Mainz, Germany) was used. Aliquots (100 mg each) of an oligomer mixture were dissolved in ammonium acetate buffer $(0.15$ $\mathrm{M}, \mathrm{pH} 4.5$ ) and separated using the same buffer as the mobile phase with a flow rate of $0.6 \mathrm{ml} / \mathrm{min}$. The oligomers were collected in $3 \mathrm{ml}$ fractions, analyzed via UHPLC-ELSD-LC-MS ${ }^{1}$, and pooled accordingly. Twice the equimolar amount of $\mathrm{HCl}$ relative to the number of GlcN subunits was added to stabilize the oligomers. Ammonium acetate was removed by repeated freeze drying and dissolving in $\mathrm{H}_{2} \mathrm{O}$.

\section{Molecular modeling and docking studies}

The model of CSN with a docked GlcN hexamer (Fig. 1, Additional file 1: Figure S3) was generated using SWISS-MODEL $[49,50]$ using the crystal structure of $\mathrm{Ba}$ cillus sp. K17 chitosanase (PDB: 1V5C, amino acid sequence identity: 97.47\%) as a template. Post refinement including energy minimization stereo-chemical correction was performed using the KoBaMIN server [51]. MolProbity [52] was used to assess the geometric accuracy of the refined model. The substrate was built with the GLYCAM webserver [53], charges were assigned, hydrogens were added, and nonpolar hydrogens were merged. Docking was performed using AutoDock 4.2. The inbuilt autogrid function in AutoDock was used to generate a grid map around the enzyme's active center. The Lamarckian Genetic Algorithm with default parameters was applied and 100 conformations were generated for the substrate. The binding energy of the docked substrate was evaluated using the autoscorer function in AutoDock and the best results were visualized using PYMOL (The PYMOL Molecular Graphics System, Version 1.8 Schrödinger, LLC). 


\section{Additional file}

Additional file 1: Figure S1. Western blots of CSN, CSN-E59A, CSNY270A, and CSN-W118A. Figure S2. Quantification of $A_{1} D_{3}$. Figure S3. Selected CSN residues with a predicted or experimentally verified function in substrate binding. Figure S4. Comparison of expected and determined productive substrate positionings of $D_{5}$ and $D_{4}$ in CSN and the muteins. Table S1. Gradient elution profiles, temperatures, and flow rates of the employed UHPLC-MS ${ }^{n}$ methods. (DOCX $2671 \mathrm{~kb}$ )

\section{Abbreviations}

$A_{n}: n$-mer of $N$-acetyl-D-glucosamine; CSN: Chitosanase BspCsnMN from Bacillus sp. MN; DA: Degree of acetylation; $D_{n}$ : n-mer of D-glucosamine; DP: Degree of polymerization; GH: Glycoside hydrolase; GlcN: D-glucosamine; GICNAC: N-acetyl-D-glucosamine; HILIC: Hydrophilic interaction liquid chromatography; $\mathrm{k}_{\text {cat }}$ : Catalytic rate constant; PA: Pattern of acetylation; paCOS: Partially acetylated chito-oligosaccharides; SEC: Size-exclusion chromatography; TLC: Thin layer chromatography; UF: Ultrafiltration; UHPLC ELSD-ESI-MS: Ultra high performance liquid chromatography - evaporative light scattering detection - electrospray ionization - mass spectrometry

\section{Acknowledgements}

We would like to thank Dr. Dominique Gillet for providing chitosan polymers, and Celeste Brennecka for support in preparing the manuscript.

\section{Funding}

Research was funded by the Deutsche Bundesstiftung Umwelt DBU (German Federal Environmental Foundation) through a doctoral fellowship to EKR.

\section{Availability of data and materials}

All data generated or analyzed during this study are included in this published article [and its Additional file 1].

\section{Authors' contributions}

EKR and RS designed the constructs for the muteins of CSN. DG prepared the constructs and performed all experiments. BMM supervised the project. DG wrote the manuscript. EKR, RS, and BMM edited the manuscript. All authors read and approved the final manuscript.

\section{Ethics approval and consent to participate}

Not applicable.

\section{Consent for publication}

Not applicable.

\section{Competing interests}

The authors declare that they have no competing interests.

\section{Publisher's Note}

Springer Nature remains neutral with regard to jurisdictional claims in published maps and institutional affiliations.

\section{Received: 17 December 2018 Accepted: 21 February 2019}

Published online: 12 March 2019

\section{References}

1. Ravi Kumar MN. A review of chitin and chitosan applications. React Funct Polym. 2000;46:1-27

2. Aam BB, Heggset EB, Norberg AL, Sørlie M, Vårum KM, Eijsink VGH. Production of Chitooligosaccharides and their potential applications in medicine. Mar Drugs. 2010;8:1482-517.

3. Shukla SK, Mishra AK, Arotiba OA, Mamba BB. Chitosan-based nanomaterials: a state-of-the-art review. Int J Biol Macromol. 2013;59:46-58.

4. Das SN, Madhuprakash J, Sarma PVSRN, Purushotham P, Suma K, Manjeet K, et al. Biotechnological approaches for field applications of chitooligosaccharides (COS) to induce innate immunity in plants. Crit Rev Biotechnol. 2015;35:29-43.
5. Lodhi G, Kim Y-S, Hwang J-W, Kim S-K, Jeon Y-J, Je J-Y, et al. Chitooligosaccharide and its derivatives: preparation and biological applications. Biomed Res Int. 2014;2014:13.

6. El Gueddari NE, Schaaf A, Kohlhoff M, Gorzelanny C, Moerschbacher BM. Substrates and products of chitin and chitosan modifying enzymes. Adv Chitin Sci. 2007:10:119-26.

7. Day RB, Tanabe S, Koshioka M, Mitsui T, Itoh H, Ueguchi-Tanaka M, et al. Two Rice GRAS family genes responsive to N-Acetylchitooligosaccharide elicitor are induced by Phytoactive gibberellins: evidence for cross-talk between elicitor and gibberellin signaling in Rice cells. Plant Mol Biol. 2004; 54:261-72.

8. Nars A, Rey T, Lafitte C, Vergnes S, Amatya S, Jacquet C, et al. An experimental system to study responses of Medicago truncatula roots to chitin oligomers of high degree of polymerization and other microbial elicitors. Plant Cell Rep. 2013;32:489-502.

9. Hayafune M, Berisio R, Marchetti R, Silipo A, Kayama M, Desaki Y, et al. Chitin-induced activation of immune signaling by the rice receptor CEBiP relies on a unique sandwich-type dimerization. Proc Natl Acad Sci U S A. 2014;111:E404-13.

10. Conrath U, Beckers GJM, Langenbach CJG, Jaskiewicz MR. Priming for enhanced defense. Annu Rev Phytopathol. 2015:53:97-119.

11. Vander P, Vårum KM, Domard A, El Gueddari NE, Moerschbacher BM. Comparison of the ability of partially $\mathrm{N}$-acetylated chitosans and chitooligosaccharides to elicit resistance reactions in wheat leaves. Plant Physiol. 1998;118:1353-9.

12. Jeon YJ, Park PJ, Kim SK. Antimicrobial effect of chitooligosaccharides produced by bioreactor. Carbohydr Polym. 2001;44:71-6.

13. Omura $Y$, Shigemoto M, Akiyama T, Saimoto H, Shigemasa $Y$, Nakamura I, et al. Antimicrobial activity of chitosan with different degrees of acetylation and molecular weights. Biocontrol Sci. 2003:8:25-30.

14. Tikhonov VE, Stepnova EA, Babak VG, Yamskov IA, Palma-Guerrero J, Jansson $\mathrm{H}-\mathrm{B}$, et al. Bactericidal and antifungal activities of a low molecular weight chitosan and its N-/2(3)-(dodec-2-enyl)succinoyl/-derivatives. Carbohydr Polym. 2006:64:66-72.

15. Cord-Landwehr S, Melcher RLJ, Kolkenbrock S. Moerschbacher BM. A chitin deacetylase from the endophytic fungus Pestalotiopsis sp. efficiently inactivates the elicitor activity of chitin oligomers in rice cells. Sci Rep. 2016;6:38018.

16. Gubaeva E, Gubaev A, RL M, Cord-Landwehr S, Singh R, El Gueddari NE, et al. Slipped Sandwich' model for chitin and chitosan perception in Arabidopsis. Mol Plant-Microbe Interact. 2018. https://doi.org/10.1094/MPMI04-18-0098-R.

17. Cord-Landwehr S, Ihmor P, Niehues A, Luftmann H, Moerschbacher BM, Mormann M. Quantitative mass-spectrometric sequencing of chitosan oligomers revealing cleavage sites of chitosan hydrolases. Anal Chem. 2017; 89:2893-900.

18. Hembach L, Cord-Landwehr S, Moerschbacher BM. Enzymatic production of all fourteen partially acetylated chitosan tetramers using different chitin deacetylases acting in forward or reverse mode. Sci Rep. 2017;7:17692

19. Henrissat B, Bairoch A. Updating the sequence-based classification of glycosyl hydrolases. Biochem J. 1996;316(Pt 2):695-6.

20. Fukamizo T, Ohkawa T, Ikeda Y, Goto S. Specificity of chitosanase from Bacillus pumilus. Biochim Biophys Acta. 1994;1205:183-8.

21. Hirano K, Watanabe M, Seki K, Ando A, Saito A, Mitsutomi M. Classification of Chitosanases by hydrolytic specificity toward N $1, \mathrm{~N} 4$ -Diacetylchitohexaose. Biosci Biotechnol Biochem. 2012;76:1932-7.

22. Weikert T, Niehues A, Cord-Landwehr S, Hellmann MJ, Moerschbacher BM Reassessment of chitosanase substrate specificities and classification. Nat Commun. 2017;8:1698

23. Kulikov SN, Chirkov SN, Il'ina AV, Lopatin SA, Varlamov VP. Effect of the molecular weight of chitosan on its antiviral activity in plants. Appl Biochem Microbiol. 2006;42:200-3.

24. El Gueddari NE, Kolkenbrock S, Schaaf A, Chilukoti N, Brunel F, Gorzelanny C, et al. Chitin and chitosan modifying enzymes: versatile novel tools for the analysis of structure-function relationships of partially acetylated chitosans. Adv Chitin Sci. 2014;14:40-7

25. Kuroiwa T, Izuta H, Nabetani H, Nakajima M, Sato S, Mukataka S, et al. Selective and stable production of physiologically active chitosan oligosaccharides using an enzymatic membrane bioreactor. Process Biochem. 2009:44:283-7.

26. Qin Z, Luo S, Li Y, Chen Q, Qiu Y, Zhao L, et al. Biochemical properties of a novel chitosanase from Bacillus amyloliquefaciens and its use in membrane reactor. LWT. 2018;97:9-16. 
27. Jeon Y-J, Kim S-K. Continuous production of chitooligosaccharides using a dual reactor system. Process Biochem. 2000;35:623-32.

28. Sakai K, Katsumi R, Isobe A, Nanjo F. Purification and hydrolytic action of a chitosanase from Nocardia orientalis. Biochim Biophys Acta. 1991;1079:6572

29. Chiang C-L, Chang C-T, Sung H-Y. Purification and properties of chitosanase from a mutant of Bacillus subtilis IMR-NK1. Enzym Microb Technol. 2003;32: 260-7.

30. Pechsrichuang P, Yoohat K, Yamabhai M. Production of recombinant Bacillus subtilis chitosanase, suitable for biosynthesis of chitosanoligosaccharides. Bioresour Technol. 2013;127:407-14.

31. Boucher I, Dupuy A, Vidal P, Neugebauer W, Brzezinski R. Purification and characterization of a chitosanase from Streptomyces N174. Appl Microbiol Biotechnol. 1992;38:188-93.

32. Heggset EB, Tuveng TR, Hoell IA, Liu Z, Eijsink VGH, Vårum KM. Mode of action of a family 75 Chitosanase from Streptomyces avermitilis. Biomacromolecules. 2012:13:1733-41.

33. Nampally M, Moerschbacher BM, Kolkenbrock S. Fusion of a novel genetically engineered chitosan affinity protein and green fluorescent protein for specific detection of chitosan in vitro and in situ. Appl Environ Microbiol. 2012:78:3114-9.

34. Singh R, Weikert T, Basa S, Moerschbacher BM. Revealing mode of action and subsite specificities of a Bacillus Chitosanase. Sci Rep. 2019;9:1132.

35. Regel EK, Weikert T, Niehues A, Moerschbacher BM, Singh R. Proteinengineering of Chitosanase from Bacillus sp. MN to Alter its substrate specificity. Biotechnol Bioeng. 2018;115:863-73.

36. Adachi W, Sakihama Y, Shimizu S, Sunami T, Fukazawa T, Suzuki M, et al. Crystal structure of family $\mathrm{GH}-8$ chitosanase with subclass II specificity from Bacillus sp. K17. J Mol Biol. 2004;343:785-95.

37. Fukamizo T, Honda Y, Goto S, Boucher I, Brzezinski R. Reaction mechanism of chitosanase from Streptomyces sp. N174. Biochem J. 1995;311(Pt 2):37783.

38. Roncal T, Oviedo A, de Armentia IL, Fernández L, Villarán MC. High yield production of monomer-free chitosan oligosaccharides by pepsin catalyzed hydrolysis of a high deacetylation degree chitosan. Carbohydr Res. 2007; 342:2750-6.

39. Winkler A, Dominguez-Nuñez J, Aranaz I, Poza-Carrión C, Ramonell K, Somerville S, et al. Short-chain chitin oligomers: promoters of plant growth. Mar Drugs. 2017;15:40.

40. Aiba S. Preparation of $\mathrm{N}$-acetylchitooligosaccharides by hydrolysis of chitosan with chitinase followed by N-acetylation. Carbohydr Res. 1994;265: 323-8.

41. Vachoud L, Zydowicz N, Domard A. Formation and characterisation of a physical chitin gel. Carbohydr Res. 1997;302:169-77.

42. Hirai A, Odani H, Nakajima A. Determination of degree of deacetylation of chitosan by 1H NMR spectroscopy. Polym Bull. 1991;26:87-94.

43. Schatz C, Viton C, Delair T, Pichot C, Alain Domard A. Typical physicochemical behaviors of chitosan in aqueous solution. Biomacromolecules. 2003;4:641-8.

44. Studier FW. Protein production by auto-induction in high-density shaking cultures. Protein Expr Purif. 2005;41:207-34.

45. Laemmli UK. Denaturing (SDS) discontinuous gel electrophoresis. Nature. 1970;277:680-5

46. Towbin H, Staehelin T, Gordon J. Electrophoretic transfer of proteins from polyacrylamide gels to nitrocellulose sheets: procedure and some applications. Proc Natl Acad Sci U S A. 1979;76:4350-4.

47. Horn SJ, VGH E. A reliable reducing end assay for chito-oligosaccharides. Carbohydr Polym. 2004;56:35-9.

48. Hamer SN, Moerschbacher BM, Kolkenbrock S. Enzymatic sequencing of partially acetylated chitosan oligomers. Carbohydr Res. 2014;392:16-20.

49. Biasini M, Bienert S, Waterhouse A, Arnold K, Studer G, Schmidt T, et al SWISS-MODEL: modelling protein tertiary and quaternary structure using evolutionary information. Nucleic Acids Res. 2014;42:W252-8.

50. Kiefer F, Arnold K, Kunzli M, Bordoli L, Schwede T. The SWISS-MODEL repository and associated resources. Nucleic Acids Res. 2009;37:D387-92.

51. Rodrigues JPGLM, Levitt M, Chopra G. KoBaMIN: a knowledge-based minimization web server for protein structure refinement. Nucleic Acids Res. 2012;40:W323-8.

52. Chen VB, Arendall WB, Headd JJ, Keedy DA, Immormino RM, Kapral GJ, et al. MolProbity: all-atom structure validation for macromolecular crystallography. Acta Crystallogr D Biol Crystallogr. 2010;66:12-21.
53. Kirschner KN, Yongye AB, Tschampel SM, González-Outeiriño J, Daniels CR, Foley BL, et al. GLYCAM06: a generalizable biomolecular force field. Carbohydrates. J Comput Chem. 2008;29:622-55.

\section{Ready to submit your research? Choose BMC and benefit from:}

- fast, convenient online submission

- thorough peer review by experienced researchers in your field

- rapid publication on acceptance

- support for research data, including large and complex data types

- gold Open Access which fosters wider collaboration and increased citations

- maximum visibility for your research: over $100 \mathrm{M}$ website views per year

At BMC, research is always in progress.

Learn more biomedcentral.com/submissions 